\title{
Performance of a Trichoderma harzianum Bentonite-vermiculite Formulation Against Fusarium Wilt in Seedling Nursery Melon Plants
}

\author{
Ainhoa Martínez-Medina ${ }^{1}$, Antonio Roldán, and Jose A. Pascual \\ CEBAS-CSIC, Department of Soil and Water Conservation and Organic \\ Waste Management, CEBAS-CSIC, Campus Universitario de Espinardo, \\ Murcia, E-30100, Spain
}

Additional index words. biocontrol agent, carrier, Fusarium oxysporum, peat, survival

\begin{abstract}
Practical use of Trichoderma harzianum requires feasible formulated products. The objective of this study was to investigate the survival and effectiveness of a $T$. harzianum bentonite-vermiculite formulation against fusarium wilt and its growthpromotion effect on melon plants under nursery conditions compared with the incorporation of this agent as a nonformulated conidia suspension. The effectiveness of the application of $T$. harzianum to melon plants was related directly to its formulation, as the formulation had a clear influence on its survival on peat. The formulated form maintained the inoculation level of $T$. harzianum colony-forming units after 8 weeks, whereas the nonformulated form reduced it by two orders of magnitude. Plants treated with the bentonite-vermiculite formulation showed a higher shoot weight and higher resistance to fusarium wilt disease.
\end{abstract}

One of the major limitations to the application of biological control agents (BCAs) such as Trichoderma species is the development of appropriately formulated products (Fravel, 2005). Although a wide range of formulations of the biofungicide Trichoderma sp. has been tested (Batta, 2004; Kolombet et al., 2008; Kücük and Kivanc, 2005; Zohar-Perez et al., 2003), they are focused on keeping the culture viable and active during storage. Some additives (protectants and carriers) have been used to increase BCA survival under adverse environmental conditions (Wraight et al., 2001). Some carriers include fine clay, peat, vermiculite, alginate, wheat, bran, talc, diatomaceous earth, and pasteurized soil (Boyetchko et al., 1998). We propose the use of bentonitevermiculite as a solid substrate for both T. harzianum proliferation and as a carrier based on the consideration that both are harmless to the environment, inexpensive, and easily available.

A solid bentonite-vermiculite formulation based on T. harzianum (CECT 20714) and the use of this agent as a nonformulated conidia suspension (direct inoculation) were both tested for their potential use as inocula for controlling fusarium wilt and promoting melon plant growth under in vivo greenhouse nursery conditions.

\footnotetext{
Received for publication 16 June 2009. Accepted for publication 12 Aug. 2009.

${ }^{1}$ To whom reprint requests should be addressed; e-mailammedina@cebas.csic.es.
}

\section{Materials and Methods}

Melon (Cucumis melo L., cv. Giotto) seeds were used as the host plant. T. harzianum (CECT 20714) was isolated from agricultural soil. To prepare the nonformulated form, T. harzianum was grown in potato dextrose agar for $6 \mathrm{~d}$ at $28^{\circ} \mathrm{C}$. Sterile Ringer solution $(10 \mathrm{~mL})$ was added to the fungal cultures and the conidia were dislodged with a plastic rod to obtain a fungal suspension containing $10^{8}$ conidia $/ \mathrm{mL}$. The formulated form was prepared by mixing $20 \mathrm{~g}$ of oat, $50 \mathrm{~mL}$ of bentonite, $100 \mathrm{~mL}$ of vermiculite (Table 1), and $60 \mathrm{~mL}$ of water. The blend was sterilized, inoculated with $T$. harzianum, and incubated at $28{ }^{\circ} \mathrm{C}$ for $8 \mathrm{~d}$ to reach the stationary phase, resulting in a fungal population of $10^{9}$ conidia/g. Fusarium oxysporum f.sp. melonis was cultivated in potato dextrose broth at $28{ }^{\circ} \mathrm{C}$ on a shaker at 120 rpm for $5 \mathrm{~d}$.

The experiment was performed in specific nursery plant polystyrene containers, with 10 cells, at Semilleros el Mirador (Murcia, Spain). The treatments were: 1) control treatment; 2) nonformulated $T$. harzianum treatment ( $T$. harzianum inoculated directly as a liquid conidial suspension); and 3 ) bentonitevermiculite $T$. harzianum formulated treatment ( $T$. harzianum was inoculated in a bentonite-vermiculite solid formulation). The treatments were prepared by mixing sterilized commercial peat with the different form of inocula. T. harzianum, both formulated and nonformulated forms, was mixed with the peat reaching a population density of $10^{6}$ conidia/g of peat. The nursery plant polystyrene containers were filled with the different treatments (10 g per cell). Each specific container was considered as a unit, and five replicates of each treatment were established. Ten melon seeds were sown (one seed per well) in the polystyrene container and covered with vermiculite. Seedlings were grown using standard nursery culture conditions, which included irrigation without any fertilizer. Four weeks after planting, $F$. oxysporum was inoculated into the peat at a concentration of $10^{4} \mathrm{conidia} / \mathrm{g}$. Eight weeks after planting, plants were harvested. Fresh and dry $\left(105^{\circ} \mathrm{C}\right.$, $5 \mathrm{~h})$ shoot weights were recorded. Plant tissues were ground before chemical analysis. Phosphorus and potassium concentrations were determined after digestion in nitric-perchloric acid (2:1) for $2 \mathrm{~h}$, phosphorus was determined by colorimetry (Murphy and Riley, 1962), and potassium by flame photometry (Schollenberger and Simon, 1945). Nitrogen concentration was determined by a modified Kjedahl method (Bremner and Mulvaney, 1982). The total foliar chlorophyll content was determined according to Arnon (Arnon, 1949).

Substrate samples were plated on potato dextrose agar (PDA) amended with 50 $\mathrm{mg} \cdot \mathrm{L}^{-1}$ rose bengal and $100 \mathrm{mg} \cdot \mathrm{L}^{-1}$ streptomycin sulfate, to calculate the number of T. harzianum colony-forming units (CFUs). Komada medium (Komada, 1975) was used for quantitative isolation of $F$. oxysporum. Plates were incubated at $28{ }^{\circ} \mathrm{C}$ for $5 \mathrm{~d}$. To assess $F$. oxysporum infection, stem segments $(\approx 1.5 \mathrm{~cm})$ above crowns were cut, surface-sterilized by soaking in $1 \%$ sodium hypochlorite, and rinsed with sterilized water. The segments were incubated on PDA at $28{ }^{\circ} \mathrm{C}$ for $6 \mathrm{~d}$, and the appearance of $F$. oxysporum colonies was considered to be indicative of infected plants.

The data were subjected to analysis of variance using SPSS software (SPSS system for Windows, Version 15.0; SPSS Inc., Chicago, IL). The statistical significance of the results was analyzed by the performance of Tukey's multiple range test $(P \leq 0.05)$.

\section{Results and Discussion}

Bentonite-vermiculite formulation treatment maintained the initial inoculation level of $T$. harzianum CFUs in the plant growth substrate after 8 weeks, whereas the nonformulated treatment reduced the initial inoculated level of T. harzianum CFUs by two orders of magnitude after 8 weeks (Fig. 1A). This low survival rate suggests the sensitivity of $T$. harzianum to environmental conditions, although seedling nurseries seem to provide

Table 1. Bentonite and vermiculite main physicochemical parameters.

\begin{tabular}{lcc}
\hline Parameter & Bentonite & Vermiculite \\
\hline pH & 9.5 & 9.9 \\
$\begin{array}{l}\text { Electrical conductivity } \\
\quad\left(\mathrm{mS} \cdot \mathrm{cm}^{-1}\right)\end{array}$ & 0.41 & 0.19 \\
Total organic carbon (\%) & 0.84 & 0.84 \\
Total nitrogen (\%) & 0.03 & 0.06 \\
Total phosphorus (\%) & 0.1 & 0.02 \\
Total potassium (\%) & 1.01 & 0.38 \\
\hline
\end{tabular}




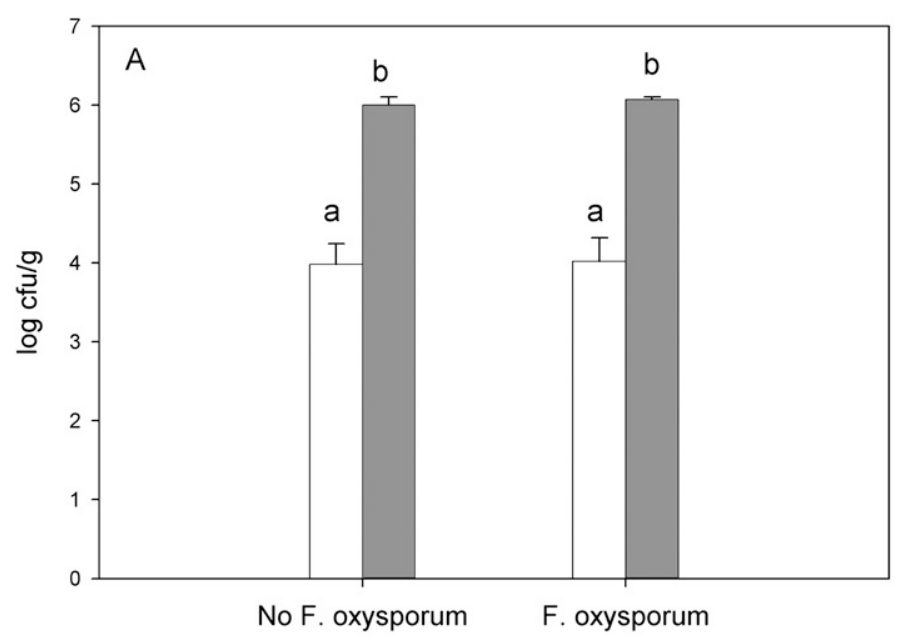

Non T. harzianum

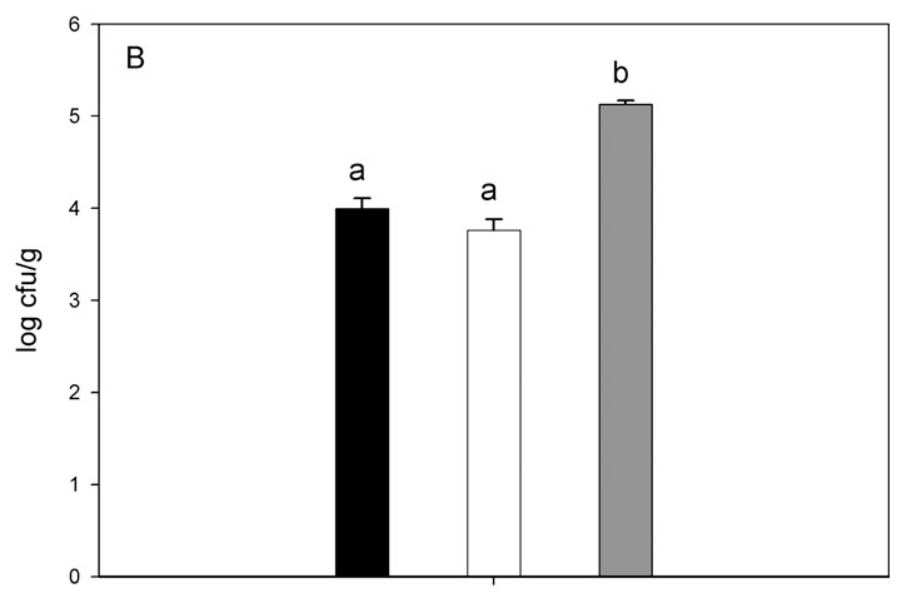

NF T. harzianum

\section{F T. harzianum}

Fig. 1. T. harzianum and F. oxysporum population. (A) T. harzianum population inoculated as a nonformulated (NF) or formulated (F) form, 8 weeks after inoculation, in the presence or absence of $F$. oxysporum. (B) F. oxysporum population, 4 weeks after inoculation, in the presence or absence of $T$. harzianum inoculated as a nonformulated or formulated form (log colony-forming units per gram of substrate). Bars indicate sD. Values with the same letter represent no significant difference between treatments according to Tukey's multiple range test $(P \leq 0.05 ; \mathrm{n}=5)$.

an optimal environment for application of BCAs. The reduction of T. harzianum population in a nonformulated treatment can be reasonably assumed to be attributed, in general, to a lack of protection against several factors, including sunlight, temperature, humidity, leaf surface exudates, and competitors (Jones and Burges, 1998). The bentonite-vermiculite formulation was found to be a suitable medium for the persistence and survival of $T$. harzianum in a nursery substrate. T. harzianum immobilization in solid beds by a clay alginate matrix results in greater survival in the face of ultraviolet irradiation than with a free cell suspension (Zohar-Perez et al., 2003). In addition, bentonite might offer protection against biological factors through the induction of the formation of microniches (Heynen et al., 1988) and formation of a physical barrier between the inoculant microorganisms and the surrounding environment (Heijnen et al., 1993). Our results indicate a clear positive effect of the solid carrier, in the bentonitevermiculite formulation treatment, on $T$. harzianum viability in melon seedlings after peat inoculation in greenhouse nursery conditions. Similar results have been observed by Bernal-Vicente et al. (2009) who observed a decrease in the number of $T$. harzianum CFUs when inoculated as a conidia suspension. However, our results contrast with a previous report in which inoculation of a solid formulation of Trichoderma atroviride C52 decreased the Trichoderma population in the rhizosphere (McLean et al., 2005).

Plants treated with the bentonitevermiculite formulation of $T$. harzianum showed a significant increase in fresh and dry weights and chlorophyll content compared with the nonformulated $T$. harzianum and with the control plants (Table 2). This biostimulant activity has been studied widely for different isolates of Trichoderma sp. (Björkman et al., 1998; Harman and Björkman, 1998; Harman et al., 2004; Ousley et al., 1994; Rabeendran et al., 2000). Several mechanisms by which Trichoderma stimulate plant development have been suggested such as the production of growth-promoting metabolites and an increase in the uptake of nutrients by the roots as a result of plantTrichoderma interaction (Altomare et al., 1999; Windham et al., 1986; Yedidia et al., 2001). These effects have important economic implications in terms of shortening the plant growth period and the time in the seedling nurseries, thereby increasing production capacity. The formulated T. harzianum form also affected nitrogen (N), phosphorus $(\mathrm{P})$, and potassium $(\mathrm{K})$ contents of plants. A significant increase was observed in plant $\mathrm{P}$ content. On the other hand, plant $\mathrm{N}$ content decreased, whereas $\mathrm{K}$ content was slightly but not significantly lower in the formulated form of T. harzianum (Table 2).
This decrease in $\mathrm{N}$ content could have been the result of competition for $\mathrm{N}$ between the plants and T. harzianum (Hodge et al., 2000; Kaye and Hart, 1997), although this decreased $\mathrm{N}$ uptake produced no adverse effect on plant growth.

Plants treated with the formulated form of T. harzianum were more resistant to fusarium wilt in the nursery. Nontreated plants and plants treated with the nonformulated $T$. harzianum form showed a higher disease incidence, which was reduced significantly only in the plants treated with the formulated T. harzianum form (Table 3 ).

Furthermore, diseased plants, treated with the bentonite-vermiculite formulation of $T$. harzianum, showed a lower decrease in fresh weight and chlorophyll content $(13 \%$ and $8 \%$ in fresh weight and chlorophyll content, respectively, with respect to noninfected plants) (Tables 2 and 3) when compared with diseased nontreated plants and diseased plants treated with the nonformulated $T$. harzianum.

The presence of $F$. oxysporum did not affect the $T$. harzianum population inoculated in either the formulated or nonformulated form (Fig. 1A); however, a significant increase in the pathogen population was found resulting from the presence of $T$. harzianum inoculated as the formulated form, but not in the nonformulated form (Fig. 1B). There are a number of reports of the biocontrol capacity

Table 2. Fresh and dry shoot weight, chlorophyll content, and nitrogen, phosphorus, and potassium content in melon plants inoculated with T. harzianum as a nonformulated (NF) and formulated (F) form 8 weeks after planting.

\begin{tabular}{|c|c|c|c|c|c|c|}
\hline & $\begin{array}{l}\text { Fresh } \\
\text { wt (g) }\end{array}$ & $\begin{array}{c}\text { Dry } \\
\text { wt (g) }\end{array}$ & $\begin{array}{c}\text { Chlorophyll } \\
\left(\mathrm{g} \cdot \mathrm{kg}^{-1}\right)\end{array}$ & $\begin{array}{c}\text { Nitrogen } \\
\left(\mathrm{g} \cdot \mathrm{kg}^{-1}\right)\end{array}$ & $\begin{array}{c}\text { Phosphorous } \\
\left(\mathrm{g} \cdot \mathrm{kg}^{-1}\right)\end{array}$ & $\begin{array}{c}\text { Potassium } \\
\left(\mathrm{g} \cdot \mathrm{kg}^{-1}\right)\end{array}$ \\
\hline N.F. T. harzianum & $5.72 \pm 0.68 \mathrm{a}$ & $0.66 \pm 0.08 \mathrm{a}$ & $0.35 \pm 0.02 \mathrm{a}$ & $19.2 \pm 0.05 b$ & $5.6 \pm 0.04 \mathrm{a}$ & $24.9 \pm 0.20 \mathrm{a}$ \\
\hline
\end{tabular}

Data are means \pm SD of five replicates. Values in the same row or column with the same letters represent no significant difference between treatments according to Tukey's multiple range test $(P \leq 0.05)$. 
Table 3. Disease incidence, fresh shoot weight, and chlorophyll content in melon plants inoculated with $T$. harzianum as a nonformulated (NF) and a formulated (F) 4 weeks after pathogen inoculation.

\begin{tabular}{lccc}
\hline & $\begin{array}{c}\text { Disease } \\
\text { incidence }(\%)\end{array}$ & $\begin{array}{c}\text { Fresh } \\
\text { wt }(\mathrm{g})\end{array}$ & $\begin{array}{c}\text { Chlorophyll } \\
\left(\mathrm{g} \cdot \mathrm{kg}^{-1}\right)\end{array}$ \\
\hline Control & $83.3 \mathrm{a}$ & $4.15 \pm 0.40 \mathrm{a}$ & $0.22 \pm 0.09 \mathrm{a}$ \\
N.F. T. harzianum & $76.6 \mathrm{a}$ & $4.38 \pm 0.17 \mathrm{a}$ & $0.24 \pm 0.13 \mathrm{a}$ \\
F. T. harzianum & $46.0 \mathrm{~b}$ & $6.17 \pm 0.73 \mathrm{~b}$ & $0.51 \pm 0.07 \mathrm{~b}$ \\
\hline
\end{tabular}

Data are means \pm SD of five replicates. Values in the same row or column with the same letters represent no significant difference between treatments according to Tukey's multiple range test $(P \leq 0.05)$.

of Trichoderma species (Howell, 2003) and various mechanisms of biocontrol have been reported such as mycoparasitism, antibiotic production, competition, or induction of plant defense (Harman et al., 2004). Because we observed an increase in the pathogen population, other mechanisms such as an induction of plant defense rather than a direct interaction of the BCA and the pathogen could explain the suppression of the disease development by T. harzianum (De Meyer et al., 1998).

In conclusion, the effectiveness of the application of $T$. harzianum to melon plants under seedling nursery conditions was related directly to its formulation, because the formulation had a clear influence on the survival of this antagonistic fungus on peat. A commercial bentonite-vermiculite formulation based on T. harzianum strain CECT 20714 could be effective in greenhouse nurseries with a double objective: 1) to enhance plant growth; and 2) to reduce the incidence of fusarium wilt in melon plants.

\section{Literature Cited}

Altomare, C., W.A. Norvell, T. Björkman, and G.E. Harman. 1999. Solubilization of phosphates and micronutrients by the plant-growth promoting and biocontrol fungus Trichoderma harzianum Rifai 1295-22. Appl. Environ. Microbiol. 65:2926-2933.

Arnon, D.I. 1949. Copper enzymes in isolated chloroplasts. Polyphenoloxidase in Beta vulgaris. Plant Physiol. 24:1-15.

Batta, Y.A. 2004. Postharvest biological control of apple gray mold by Trichoderma harzianum Rifai formulated in an invert emulsion. Crop Prot. 23:19-26.

Bernal-Vicente, A., M. Ros, and J.A. Pascual. 2009. Increased effectiveness of the Trichoderma harzianum isolate T-78 against fusarium wilt on melon plants under nursery conditions. J. Sci. Food Agr. 89:827-833.

Björkman, T., L. Blanchard, and G.E. Harman. 1998. Growth enhancement of shrunken-2 sweet corn by Trichoderma harzianum 1295-
22: Effect of environmental stress. J. Amer. Soc. Hort. Sci. 123:35-40.

Boyetchko, S., E. Pedersen, Z. Punja, and M. Reddy. 1998. Formulations of biopesticides, p. 487-508. In: Hall, F.R. and J.J. Menn (eds.). Biopesticides: Use and delivery. Humana Press, Totowa, NJ.

Bremner, J.M. and C.S. Mulvaney. 1982. Nitrogentotal, p. 595-624. In: Page, A.L., R.H. Miller, and D.R. Keeney (eds.). Methods of soil analysis. ASA, Madison, WI

De Meyer, G., J. Bigirimana, Y. Elad, and M. Höfte. 1998. Induced systemic resistance in Trichoderma harzianum T39 biocontrol of Botrytis cinerea. Eur. J. Plant Pathol. 104: 279-286.

Fravel, D.R. 2005. Commercialization and implementation of biocontrol. Annu. Rev. Phytopathol. 43:337-359.

Harman, G.E. and T. Björkman. 1998. Potential and existing uses of Trichoderma and Gliocladium for plant disease control and plant growth enhancement, p. 229-266. In: Harman, G.E. and C.P. Kubicek (eds.). Trichoderma and gliocladium. Vol. 2. Enzymes, biological control and commercial applications. Taylor \& Francis, London, UK.

Harman, G.E., C.R. Howell, A. Viterbo, I. Chet, and M. Lorito. 2004. Trichoderma species opportunistic, avirulent plant symbionts. Nat. Rev. Microbiol. 2:34-56.

Heijnen, C.E., C. Chenu, and M. Robert. 1993. Micro-morphological studies on clay-amended and unamended loamy sand, relating survival of introduced bacteria and soil structure. Geoderma 56:195-207.

Heynen, C.E., J.D. van Elsas, P.J. Kuikman, and J.A. van Veen. 1988. Dynamics of Rhizobium leguminosarum biovar trifolii introduced into soil; the effect of bentonite clay on predation by protozoa. Soil Biol. Biochem. 20:483488.

Hodge, A., J. Stewart, D. Robinson, B.S. Griffiths, and A.H. Fitter. 2000. Competition between roots and soil micro-organisms for nutrients from nitrogen-rich patches of varying complexity. J. Ecol. 88:150-164.

Howell, C.R. 2003. Mechanisms employed by Trichoderma species in the biological control of plant diseases: The history and evolution of current concepts. Plant Dis. 87:4-10.
Jones, K.A. and H.D. Burges. 1998. Technology of formulation and application, p. 7-30. In: Burges, H.D. (ed.). Formulation of microbial biopesticides. Kluwer Academic Publishers, London, UK.

Kaye, J.P. and S.C. Hart. 1997. Competition for nitrogen between plants and soil microorganisms. Trends Ecol. Evol. 12:139-143.

Kolombet, L.V., S.K. Zhigletsova, N.I. Kosareva, E.V. Bystrova, V.V. Derbyshev, S.P. Krasnova, and D. Schisler. 2008. Development of an extended shelf-life, liquid formulation of the biofungicide Trichoderma asperellum. World J. Microbiol. Biotechnol. 24:123-131.

Komada, H. 1975. Development of a selective medium for cuantitative isolation of Fusarium oxysporum from natural soil. Rev. Plant Prot. Res. 8:114-124.

Kücük, C. and M. Kivanc. 2005. Effect of formulation on the viability of biocontrol agent Trichoderma harzianum conidia. Afr. J. Biotechnol. 4:483-486.

McLean, K.L., J. Swaminathan, C.M. Frampton, J.S. Hunt, H.J. Ridgway, and A. Stewart. 2005. Effect of formulation on the rhizosphere competence and biocontrol ability of Trichoderma atroviride C52. Plant Pathol. 54:212-218.

Murphy, J. and J.P. Riley. 1962. A modified single solution method for the determination of phosphate in natural waters. Anal. Chim. Acta 27: 31-36.

Ousley, M.A., J.M. Lynch, and J.M. Whipps. 1994. Potential of Trichoderma spp. as consistent plant growth stimulators. Biol. Fertil. Soils 17:85-90.

Rabeendran, N., D.J. Moot, E.E. Jones, and A Stewart. 2000. Inconsistent growth promotion of cabbage and lettuce from Trichoderma isolates. NZ Plant Prot. 53:143-146.

Schollenberger, C.J. and R.H. Simon. 1945. Determination of exchange capacity and exchangeable bases in soils. Soil Sci. 59:13-24.

Windham, M.T., Y. Elad, and R. Baker. 1986. A mechanism for increased plant growth induced by Trichoderma spp. Phytopathology 6:518521.

Wraight, S.P., M.A. Jackson, and S.L. de Kock. 2001. Production, stabilisation and formulation of fungal biocontrol agents, p. 253-287. In: Butt, T.M., C. Jackson, and N. Magan (eds.). Fungi as biocontrol agents. CABI Publishing, Wallingford, CT.

Yedidia, I., A.K. Srivastva, Y. Kapulnik, and I. Chet. 2001. Effect of Trichoderma harzianum on microelement concentrations and increased growth of cucumber plants. Plant Soil 235: 235-242.

Zohar-Perez, C., L. Chernin, I. Chet, and A. Nussinovitch. 2003. Structure of dried cellular alginate matrix containing fillers provides extra protection for microorganisms against UVC radiation. J. Radiat. Res. (Tokyo) 160: 198-204. 